\title{
Effects of Iron Deficiency on Magnetic Properties of NiZn Ferrites
}

\author{
J. Sláma, M. ŠOKA*, M. UŠÁKOVÁ And E. UŠÁK \\ Institute of Electrical Engineering, Slovak University of Technology in Bratislava, \\ Ilkovičova 3, 81219 Bratislava, Slovakia
}

\begin{abstract}
Selected magnetic properties of $\left(\mathrm{Ni}_{0.33} \mathrm{Zn}_{0.67}\right)_{1+x} \mathrm{Fe}_{2-x} \mathrm{O}_{4}$ ferrite (where $\left.x=0,0.08,0.12,0.2\right)$ are investigated. The Curie temperature and the maximum flux density of $\mathrm{Ni}_{0.33} \mathrm{Zn}_{0.67}$ ferrites with Fe deficiency increases due to the increase in super-exchange interactions between A-B sites of spinel structure. Deficiency of Fe results in a decrease of grain size, susceptibility and permeability, meanwhile the coercivity and resonant frequency increase. The physical characteristics of the resulting products were investigated by X-ray diffraction, Mössbauer spectroscopy and thermomagnetic analysis. Deficiency of Fe in the studied composition extends temperature scale of the ferrite applicability, as well as enhances a temperature stability of ferrite.
\end{abstract}

DOI: 10.12693/APhysPolA.137.892

PACS/topics: NiZn ferrites, iron deficiency, magnetic properties

\section{Introduction}

NiZn ferrites are the widely used soft magnetic materials for high-frequency applications thanks to their high electrical resistivity, permeability, low losses and cost. As it is known, the deficiency of Fe affects the magnetic properties of NiZn ferrites, and results in the variation of the chemical composition and structure of NiZn ferrites. A systematic study of Fe-deficient NiZn ferrite is an interesting problem and changing the iron content in the composition is one of the ways to determine the magnetic properties of such materials [1-5]. When evaluating the effects of Fe deficit in such system to modify its final properties, one should find a suitable type of the initial composition of NiZn ferrite. In our case, as the initial composition to study the Fe deficiency effect on magnetic properties of ferrite, the $\mathrm{Ni}_{0.33} \mathrm{Zn}_{0.67} \mathrm{Fe}_{2} \mathrm{O}_{4}$ was chosen. Thus the influence of non-stoichiometry on the magnetic properties of $\left(\mathrm{Ni}_{0.33} \mathrm{Zn}_{0.67}\right)_{1+x} \mathrm{Fe}_{2-x} \mathrm{O}_{4}$ for $x=0.00$ up to $x=0.20$ was investigated.

\section{Experimental methods used}

The ferrites were prepared by wet method from an organo-metallic precursor with glycine, using lowtemperature auto-combustion. Samples were prepared at various sintering temperatures $\left(T_{s}\right)$. The thermomagnetic analysis was performed on the basis of magnetic susceptibility measured with automated balancing bridge Kappabridge KLY-2 at frequency $960 \mathrm{~Hz}$. The phase compositions observed by thermomagnetic curves were compared with the Mössbauer spectroscopy results using the spectrometer with ${ }^{57} \mathrm{Co}(\mathrm{Rh})$ source, and with PAN analytical X'PertPRO diffractometer using $\mathrm{CoK}_{\alpha}$ source.

*corresponding author; e-mail: martin.soka@stuba.sk
The average grain size was calculated by the Scherrer equation. The magnetic properties at low frequencies were evaluated by means of computer-controlled hysteresisgraph built-up from commercially available measuring instruments. The experimental set-up allows usage of hardware as well as software feedback to control the waveform shape of either exciting field $H(t)$, or flux density $B(t)$. High-frequency magnetic properties were measured by automated equipment using network and/or impedance analyzer. The ferrite samples prepared with composition $\left(\mathrm{Ni}_{0.33} \mathrm{Zn}_{0.67}\right)_{1+x} \mathrm{Fe}_{2-x} \mathrm{O}_{4}$, where $x=0.00$, $0.08,0.12$, and 0.20 , were used for the experiments.

\section{Results and discussion}

XRD patterns of ferrites for samples with particular substitutions $x=0.00, \ldots, 0.20$ were measured. Rietveld method as implemented in the DiffracPlusTopas program (Bruker AXS, version 4.2) was used for determining crystallographic parameters and estimation of weight fractions of as-identified oxides. In the ferrite with initial composition $\mathrm{Ni}_{0.33} \mathrm{Zn}_{0.67} \mathrm{Fe}_{2} \mathrm{O}_{4}$ (sample with $x=0$ ) sintered at $1200^{\circ} \mathrm{C} / 6 \mathrm{~h}$, two crystalline phases were identified. The first one was a spinel-type NiZn ferrite phase having the lattice parameter $a=8.4146 \AA$, the crystallite size $D=417 \mathrm{~nm}$, and the weight fraction $w=99.4 \%$. The second phase was identified as traces of $\mathrm{ZnO}$, (zincite) with the crystallite size $D_{z}=126 \mathrm{~nm}$, and weight fraction $w=0.6 \%$. In the case of samples with substitutions $x=0.08,0.12$, and 0.20 sintered at $1200^{\circ} \mathrm{C} / 6 \mathrm{~h}$, also two crystalline phases were identified. In Fig. 1 an example of the XRD patterns of $\mathrm{Ni}_{0.396} \mathrm{Zn}_{0.804} \mathrm{Fe}_{1.8} \mathrm{O}_{4}$ ferrites (with Fe-deficient content $x=0.2$ ) sintered at $1200^{\circ} \mathrm{C} / 6 \mathrm{~h}$ is shown. The first phase was identified as a spinel-type NiZn ferrite having the lattice parameter $a=8.4035 \AA$, the crystallite size $D=315 \mathrm{~nm}$, and weight fraction $w=93.3 \%$. The second phase was identified again as the $\mathrm{ZnO}$ having the crystallite size $D_{z}=131 \mathrm{~nm}$, and the weight fraction $w=6.7 \%$. 


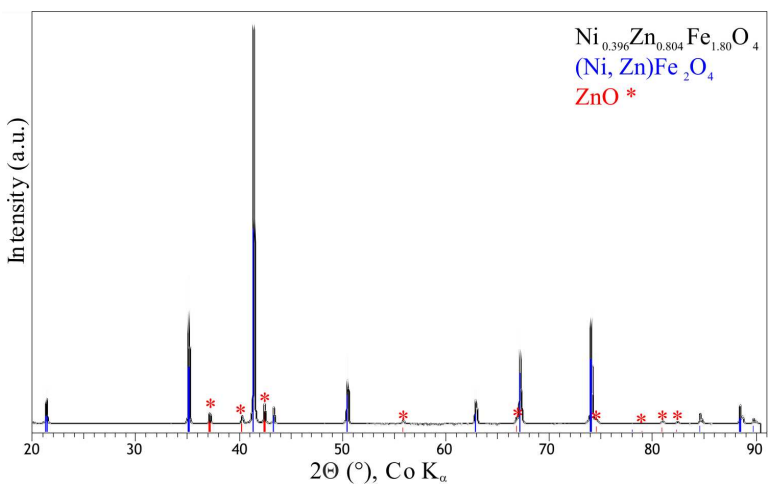

Fig. 1. X-ray diffraction patterns made for $\mathrm{Ni}_{0.396} \mathrm{Zn}_{0.804} \mathrm{Fe}_{1.8} \mathrm{O}_{4}$ ferrite samples.

The selected properties of prepared TABLE I $\left(\mathrm{Ni}_{0.33} \mathrm{Zn}_{0.67}\right)_{1+x} \mathrm{Fe}_{2-x} \mathrm{O}_{4}$ ferrites.

\begin{tabular}{l|c|c|c|c|c}
\hline \hline \multicolumn{1}{c|}{$x$} & 0 & 0.08 & 0.12 & 0.2 & 0.2 \\
\hline$B_{\max }(T)$ & 0.178 & 0.226 & 0.185 & 0.209 & - \\
$H_{c}[\mathrm{~A} / \mathrm{m}]$ & 92.1 & 193.5 & 206.7 & 241.6 & - \\
$\mu_{i}$ & 329 & 172 & 130 & 76 & - \\
$T_{\mathrm{C}}\left[{ }^{\circ} \mathrm{C}\right]$ & $110 / 106$ & 152 & 182 & 220 & - \\
$\mathrm{ZnO}[\%]$ & 0.58 & 4.424 & 7.415 & 6.687 & - \\
$\operatorname{size}[\mathrm{nm}]$ & 416.8 & 314.7 & 294.7 & 315.2 & - \\
$T_{s}\left[{ }^{\circ} \mathrm{C}\right]$ & 1200 & 1200 & 1200 & 1200 & 1000 \\
$\mu^{\prime}$ & 675 & 90 & 40 & 36 & 25 \\
$f_{r}[\mathrm{MHz}]$ & 5 & 49 & 49 & 55 & 101 \\
$\Delta f[\mathrm{MHz}]$ & $(0.0-1.2)$ & $(0-9)$ & $(0-9)$ & $(0-13)$ & $(0-47)$
\end{tabular}

The weight fractions of $\mathrm{ZnO}$ and the crystallite sizes of NiZn ferrite for other two samples with $x=0.08$ and 0.12 can be found in Table I. In the case of $\mathrm{ZnO}$, its phase increases while the crystallite size $D$ decreases due to $\mathrm{Fe}$ deficiency. On other hand, $D$ increases with $T_{s}$.

Mössbauer spectra of the samples were measured at room temperature. Results for initial samples $\mathrm{Ni}_{0.33} \mathrm{Zn}_{0.67} \mathrm{Fe}_{2} \mathrm{O}_{4}$ and $\mathrm{Ni}_{0.396} \mathrm{Zn}_{0.804} \mathrm{Fe}_{1.8} \mathrm{O}_{4}$, sintered at $1200^{\circ} \mathrm{C} / 6 \mathrm{~h}$, are shown in Fig. 2. The fitting model of spectra exhibit two components: one distribution corresponding to the magnetic phase of the sample, and other one corresponding to the non-magnetic phase of the sample. Mössbauer spectrum of initial $\mathrm{Ni}_{0.33} \mathrm{Zn}_{0.67} \mathrm{Fe}_{2} \mathrm{O}_{4}$ ferrite, shown in Fig. 2a, has the hyperfine field distribution area of $96 \%$, and quadrupole splitting distribution area of $4 \%$. Mössbauer spectrum of a sample with Fe-deficient content $x=0$, is relaxation spectra rather than normal Zeeman spectra. Exceptionally it exhibits broad magnetic and quadrupole inhomogeneity [6]. Mössbauer spectrum of $\mathrm{Ni}_{0.396} \mathrm{Zn}_{0.804} \mathrm{Fe}_{1.8} \mathrm{O}_{4}$ ferrite, shown in Fig. 2b, has the hyperfine field distribution of $99 \%$, and quadrupole splitting distribution area of $1 \%$. Note that the distribution of magnetic component in the spectrum increases with decreasing contribution of $\mathrm{Fe}^{3+}$ in the sample. This is clearly seen in the case of
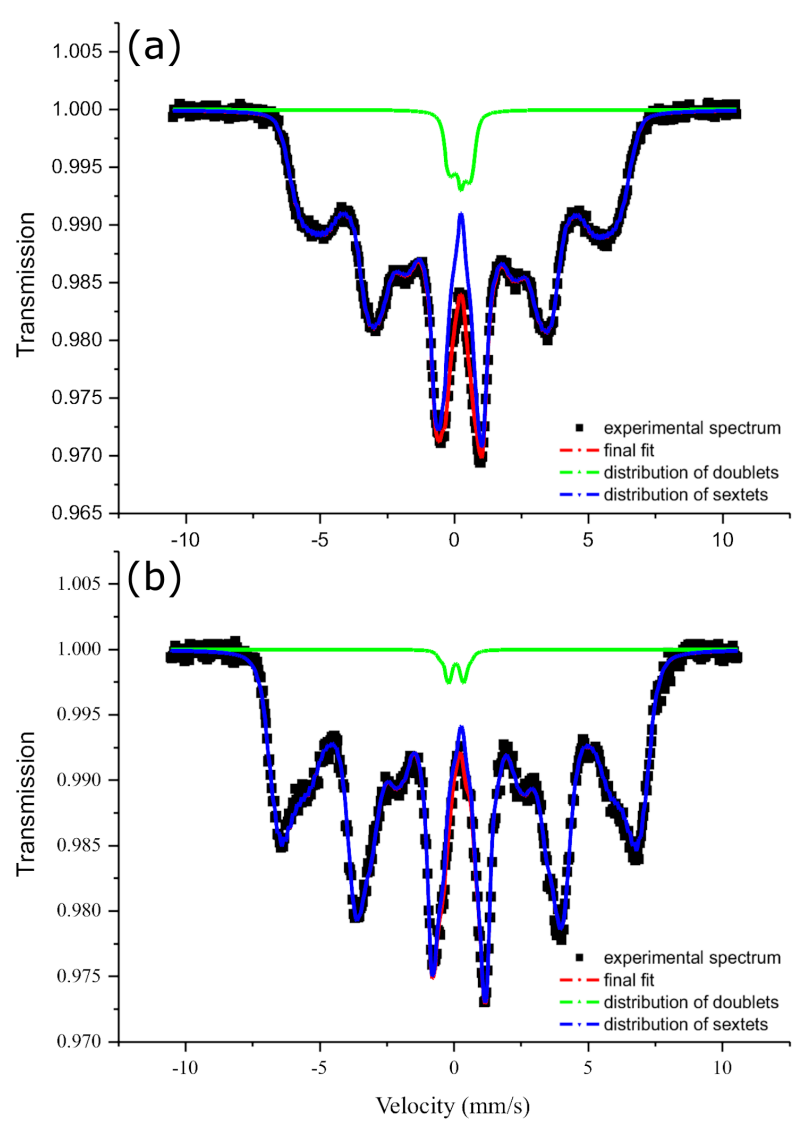

Fig. 2. The Mössbauer spectra of $\mathrm{Ni}_{0.33} \mathrm{Zn}_{0.67} \mathrm{Fe}_{2} \mathrm{O}_{4}$ and (b) $\mathrm{Ni}_{0.396} \mathrm{Zn}_{0.804} \mathrm{Fe}_{1.8} \mathrm{O}_{4}$.

(a)

those spectra that already display a Zeeman pattern [6]. Moreover, it is in line with the increase of super-exchange interactions between A-B sites of spinel, and also with the increase of $T_{\mathrm{C}}$.

As example, Fig. 3 shows the temperature dependencies of magnetic susceptibility $\chi(T)$ of $\mathrm{Ni}_{0.33} \mathrm{Zn}_{0.67} \mathrm{Fe}_{2} \mathrm{O}_{4}$ and $\mathrm{Ni}_{0.396} \mathrm{Zn}_{0.804} \mathrm{Fe}_{1.8} \mathrm{O}_{4}$ ferrite samples. In case of $\mathrm{Ni}_{0.33} \mathrm{Zn}_{0.67} \mathrm{Fe}_{2} \mathrm{O}_{4}$ samples, they all came from the same batch sintered at three selected temperature values (from $850^{\circ} \mathrm{C} / 6 \mathrm{~h}$ to $1050^{\circ} \mathrm{C} / 6 \mathrm{~h}$ with linear step of $\left.100^{\circ} \mathrm{C}\right)$. The Curie temperatures of these samples were $T_{\mathrm{C}}=106^{\circ} \mathrm{C}$. Figure 3 shows also $\chi(T)$ of $\mathrm{Ni}_{0.396} \mathrm{Zn}_{0.804} \mathrm{Fe}_{1.8} \mathrm{O}_{4}$ ferrite samples for which $T_{\mathrm{C}}=220^{\circ} \mathrm{C}$. The Curie temperature increased roughly twice, from 106 up to $220^{\circ} \mathrm{C}$ when Fe-deficient content $x$ in the composition varied from 0 to 0.2 . The values of $\chi(T)$ increased with the sintering temperature $T_{s}$. When $T_{s}<1050{ }^{\circ} \mathrm{C}$, there were no pronounced changes of $T_{\mathrm{C}}$ for all Fe-deficient samples observed in the $\chi(T)$ curves behaviour. The crystal structure was found to be a magnetic monophasic. For $T_{s}>1200^{\circ} \mathrm{C}$, the increase of $\mathrm{ZnO}$ phase with the amount of Fe deficiency and $T_{s}$, was found. The $\chi(T)$ dependencies for samples sintered at lower temperatures $T_{s}$ exhibited a Hopkinson peak close to $T_{\mathrm{C}}$. This fact confirms the phase purity and particle size homogeneity of ferrite powders [5]. 


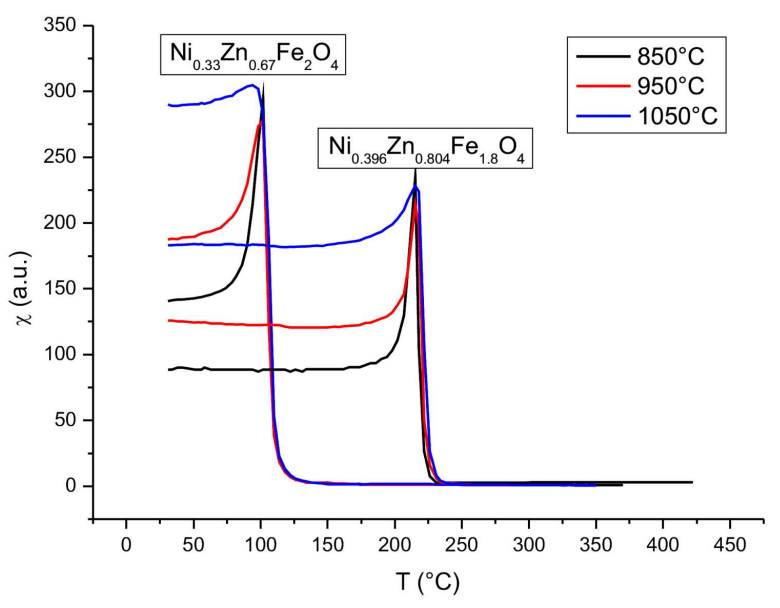

Fig. 3. Magnetic susceptibility temperature dependencies of $\mathrm{Ni}_{0.33} \mathrm{Zn}_{0.67} \mathrm{Fe}_{2} \mathrm{O}_{4}$ and $\mathrm{Ni}_{0.396} \mathrm{Zn}_{0.804} \mathrm{Fe}_{1.8} \mathrm{O}_{4}$ ferrite.

In case of $\mathrm{Ni}_{0.33} \mathrm{Zn}_{0.67} \mathrm{Fe}_{2} \mathrm{O}_{4}$ ferrite a mixed structure was detected. The part of $\mathrm{Ni}^{2+}$ ions was substituted by $\mathrm{Zn}^{2+}$ ions, the 0.67 of $\mathrm{Zn}^{2+}$ ions took the $\mathrm{A}$ site and the equivalent number of $0.67 \mathrm{Fe}^{3+}$ ions was moved from A site to B site. Consequently, the magnetic moment $m_{T}$ has raised, according to the theoretical model

$$
\begin{aligned}
& \left(\mathrm{Zn}_{0.67}^{2+} \mathrm{Fe}_{0.33}^{3+}\right)\left[\mathrm{Ni}_{0.33}^{2+} \mathrm{Fe}_{1.67}^{3+}\right] \mathrm{O}_{4}, \\
& m_{T}=-m_{\mathrm{A}}+m_{\mathrm{B}}=-(1.65) \mu_{\mathrm{B}}+[0.726+8.35] \mu_{\mathrm{B}},
\end{aligned}
$$

where the magnetic moment of $\mathrm{Fe}^{3+}$ ions is equal $5 \mu_{\mathrm{B}}$, the magnetic moment of $\mathrm{Ni}^{2+}$ ions is equal $2.2 \mu_{\mathrm{B}}$, and $\mu_{\mathrm{B}}$ is Bohr magneton. The () parentheses in above equation denote the ions localization in A sites, while the square brackets [] show the localization of ions in B sites. According to that, the theoretical total magnetic moment $m_{T}$ at right side of (1) is expressed. However, the $B$ lattice should be divided to sublattices $B_{1}$ and $\mathrm{B}_{2}$ due to Yafet-Kittel canting. The measured moment $m_{E}=4.25 \mu_{\mathrm{B}}$ turns out to be smaller than theoretical value, $m_{E}<m_{T}$ [7]. Since the B-B super exchange interactions are getting stronger, the effective moment $m_{\mathrm{B} E}$ in $\mathrm{B}$ sites given by the sum of the projections of moments of both $\left(\mathrm{B}_{1}, \mathrm{~B}_{2}\right)$ sublattices to ferrimagnetic axis, becomes smaller than $m_{\mathrm{B}}$, i.e., $m_{\mathrm{B} E}<m_{\mathrm{B}}$. In connection with it, the $\mathrm{A}-\mathrm{B}$ super-exchange interactions become small. This might explain the low value $T_{\mathrm{C}}=106{ }^{\circ} \mathrm{C}$ in $\mathrm{Ni}_{0.33} \mathrm{Zn}_{0.67} \mathrm{Fe}_{2} \mathrm{O}_{4}$ sample.

In $\mathrm{Ni}_{0.396} \mathrm{Zn}_{0.804} \mathrm{Fe}_{1.8} \mathrm{O}_{4}$ ferrite we can assume that $\mathrm{Fe}$ deficiency of the initial composition may affect the change of the theoretical $m_{T}$, according to the model

$$
\begin{aligned}
& \left(\mathrm{Zn}_{0.604}^{2+} \mathrm{Fe}_{0.396}^{3+}\right)\left[\mathrm{Ni}_{0.396}^{2+} \mathrm{Fe}_{1.404}^{3+}\right] \mathrm{O}_{4-\gamma}+\mathrm{ZnO}, \\
& m_{T}=-(1.98) \mu_{\mathrm{B}}+[0.8712+7.02] \mu_{\mathrm{B}}=-m_{A}+m_{B} .
\end{aligned}
$$

By the reduction of $\mathrm{Fe}^{3+}$ ions in $\mathrm{B}$ sites and rise of $\mathrm{Fe}^{3+}$ in $\mathrm{A}$ sites the $\mathrm{A}-\mathrm{B}$ interactions strengthen, which results in the increase of $T_{\mathrm{C}}$ to approximately $220^{\circ} \mathrm{C}$. Consequently, the $\mathrm{B}-\mathrm{B}$ interactions are reduced, the cant-

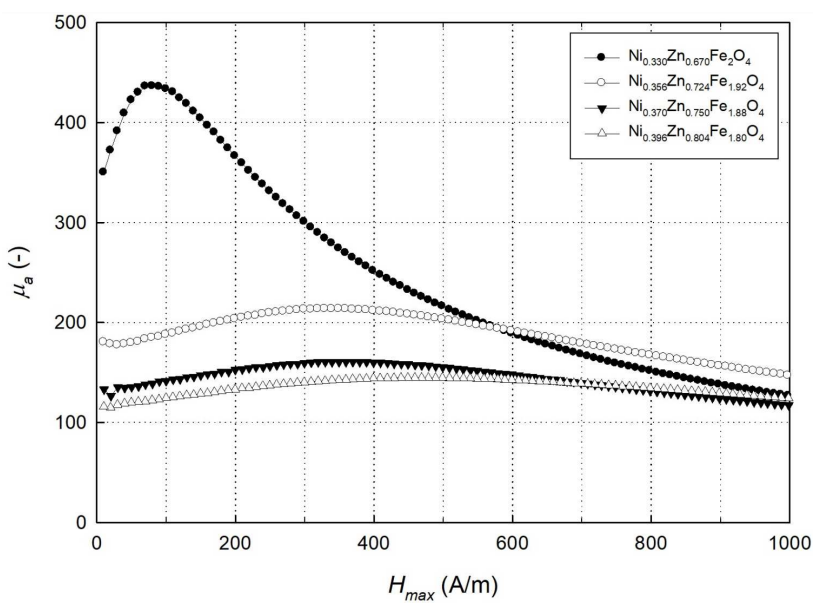

Fig. 4. The dependencies of the relative amplitude permeability $\mu_{a}$ upon the exciting field amplitude at sinusoidal field waveform of the ferrite samples sintered at $1200^{\circ} \mathrm{C}$.

ing angle decreases and the projections of partial moments of both sublattices $\left(\mathrm{B}_{1}, \mathrm{~B}_{2}\right)$ increase together with the real $m_{E}$ value and the value of maximum induction $B_{\max }$. Nevertheless, theoretical calculations of $m_{\mathrm{B}}$ still indicate lower values, see (2). Thus, deficiency of Fe causes that the canting angle decreases while the effective magnetic moment $m_{\mathrm{B} E}$ in $\mathrm{B}$ sites increases. In general, it means an increase $B_{\max }$ at $H_{\max }=2000 \mathrm{~A} / \mathrm{m}$, despite the fact that the $H_{\mathrm{c}}$ values continue their increasing trend (see Table I). The maximum flux density $B_{\max }$ values are characteristic when approaching the saturation regime, which is structurally-sensitive process.

The influence of insufficiency of the Fe ions on the relative amplitude permeability $\mu_{a}$ is clearly visible in Fig. 4. The dependencies of $\mu_{a}$ are shown upon the exciting field amplitude at sinusoidal field waveform of the ferrite samples sintered at $1200^{\circ} \mathrm{C}$. Note that the maximum amplitude permeability substantially decreases with the Fe ions deficiency. Extrapolating the curves in Fig. 4 to zero field, one can also find the initial permeabilities $\mu_{i}$. Results are given in Table I. The observed decrease of $\mu_{i}$ with increasing Fe deficiency can be attributed to increasing contribution of $\mathrm{Ni}$, as well as, to the variation of grain size and porosity.

\section{Conclusions}

As can be seen from the experiments presented here, the level of Fe deficiency strong affects the Curie temperature, structural and magnetic properties of substituted initial $\mathrm{Ni}_{0.33} \mathrm{Zn}_{0.67}$ ferrites. The increase of $T_{\mathrm{C}}$ with Fe deficiency can be attributed to the decrease of the amount of $\mathrm{Fe}$ ions in B-sites, and increase of $\mathrm{Fe}$ ions in A-sites, consequently increasing $\mathrm{A}-\mathrm{B}$ super-exchange interactions. Further, due to the reduction of the canting angle such increase is responsible for the increase of effective magnetic moment in B sites, and the increase of $B_{\max }$. However, the decrease of susceptibility, initial and 
amplitude permeability, the increase of coercivity and resonant frequency with Fe deficiency are probably due to increasing contribution of $\mathrm{Ni}$, as well as, to the variation of grain size and porosity. The $\mathrm{Ni}_{0.33} \mathrm{Zn}_{0.67}$ ferrite powders with appropriate level of iron deficiency can also be used as magnetic fillers, for example, in the ferrite polymers composites for various microwave applications at a higher frequency range.

\section{Acknowledgments}

This work was jointly supported by the Slovak Research and Development Agency under the contracts No. APVV-15-0257 and APVV-16-0059, and by VEGA agency of the Slovak Republic, under the projects No. $1 / 0405 / 16$ and $1 / 0320 / 19$. The authors would like to thank Petr Bezdička, Institute of Inorganic Chemistry of the ASCR for XRD patterns measurements.

\section{References}

[1] X. He, Z. Zhang, Z. Ling, Ceram. Int. 34, 1409 (2008).

[2] X. Tang, H. Zhang, H. Su, Z. Zhong, F. Bai, IEEE Trans. Magn. 47, 4332 (2011).

[3] A. Grusková, J. Sláma, M. Ušáková, M. Šoka, R. Dosoudil, J. Degmová, Acta Phys. Pol. A 118, 780 (2010).

[4] M. Yan, J. Hu, J. Magn. Magn. Mater. 305, 171 (2006).

[5] J. Sláma, M. Šoka, A. Grusková, A. González, V. Jančárik, J. Electr. Eng. 62, 239 (2011).

[6] J.M. Daniels, A. Rosencwaig, Can. J. Phys. 48, 381 (1970).

[7] E.W. Gorter, Phillips Res. Rept. 9, 295 (1954). 